\title{
THE INFLUENCE OF ASYNCHRONOUS BLENDED PROBLEM-BASED LEARNING ON RETENTION AND LEARNING MOTIVATION OF MIDWIFERY STUDENTS
}

\author{
Purwandyarti Apriliani $^{1 *}$, Ike Rostikawati Husen², Dany Hilmanto ${ }^{3}$ \\ ${ }^{1}$ Midwifery Master Degree Student, Universitas Padjadjaran, Bandung - INDONESIA \\ ${ }^{2}$ Faculty of Medicine, Universitas Padjadjaran, Bandung - INDONESIA \\ ${ }^{3}$ Faculty of Medicine, Universitas Padjadjaran, Bandung - INDONESIA
}

\begin{abstract}
Background: According to 21st century priorities in the Global Strategy On Human Resources For Health: Workforce 2030, the abilities of medical practices must be appropiate with the demands of the society. To realize the abilities of medical practices which are apropriate with the demands of the society, are using learning methods that encourage a more active learning process, thereby encouraging the activation of long term memory through the introduction of realistic and contextual cases that can increase the cognitive retention of students. Problem based learning method (PBL) has several limitations. One of them is the high demand of educators in number. Asynchronous blended problem based learning method (ABLE-PBL) is an instructional innovation that may be used in midwifery school institutions that have limited number of educators but they want to optimize the learning process and produce quality graduates who are competent in accordance with the demands of the society. The aim of this study is to know the influence of ABLE-PBL and PBL method on cognitive retention and student learning motivation.
\end{abstract}

Method: This study conducted using a quantitative approach with total sample 37 Universitas Padjadjaran Midwifery students who are fulfilling the inclusion and exclusion criteria, from March to June 2018 by cross over method.

Results: This study showed that there was no difference between retention score 1 and retention score 2 of intervention group (ABLE-PBL) and control group (PBL) by using mann-whitney test $(p>0,05), A B L E-P B L$ and PBL had no difference in affecting cognitive retention and motivation by using chi square test $(p>0.05)$.

Conclusion: ABLE-PBL method and PBL method has no difference in affecting cognitive retention and student learning motivation.

Keywords: cognitive retention, learning motivation, asynchronous blended problem based learning, problem based learning

\begin{abstract}
ABSTRAK
Latar belakang: Prioritas abad ke-21 dalam Global Strategy On Human Resourcesfor Health: Workforce 2030, keterampilan tenaga kesehatan harus sesuai dengan kebutuhan masyarakat saat ini dan masa depan. Salah satu cara mewujudkan keterampilan tenaga kesehatan yang sesuai dengan kebutuhan masyarakat menggunakan metode pembelajaran yang mendorong proses belajar yang lebih aktif, sehingga dapat mendorong aktivasi long term memory melalui pengenalan kasus yang realistik dan kontekstual yang dapat meningkatkan retensi kognitif peserta didik. Metode PBL memiliki keterbatasan salah satunya adalah meningkatnya jumlah kebutuhan tenaga pendidik. Metode ABLE-PBL merupakan inovasi pembelajaran yang dapat digunakan pada institusi pendidikan kebidanan yang memiliki keterbatasan jumlah tenaga pendidik namun tetap ingin mengoptimalkan proses pembelajaran dan menghasilkan kualitas lulusan
\end{abstract}

*corresponding author, contact: purwandyapril@gmail.com 
yang kompeten sesuai dengan kebutuhan masyarakat. Tujuan Penelitian ini adalah mengetahui pengaruh ABLE-PBL dan PBL terhadap retensi kognitif dan motivasi belajar mahasiswa.

Metode: Penelitian kuantitatif dengan metode cross over. Sampel yang digunakan adalah seluruh mahasiswa diploma IV kebidanan Universitas Padjadjaran yang memenuhi kriteria inklusi dan tidak memenuhi kriteria eksklusi sebanyak 37 mahasiswa. Penelitian dilakukan pada bulan Maret-Juni 2018.

Hasil: Tidak ada perbedaan skor retensi 1 dan retensi 2 antara kelompok intervensi (ABLE-PBL) dan kelompok kontrol (PBL) dengan mann-whitney test ( $p>0,05)$, metode ABLE-PBL dan PBL tidak memiliki perbedaan dalam mempengaruhi retensi kognitif dan motivasi dengan chi square test $(p>0,05)$.

Kesimpulan: Metode ABLE-PBL dan metode PBL tidak memilki perbedaan dalam mempengaruhi retensi kognitif dan motivasi belajar mahasiswa.

Kata kunci: Retensi Kognitif, Motivasi Belajar, Asyncronous blended problem based learning, Problem based learning

\section{PENDAHULUAN}

Prioritas abad ke-21 dalam Global Strategy On Human Resources for Health: Workforce 2030, keterampilan tenaga kesehatan harus sesuai dengan kebutuhan masyarakat saat ini dan dimasa depan. ${ }^{1}$ Salah satu mewujudkan keterampilan tenaga kesehatan yang sesuai dengan kebutuhan masyarakat menggunakan metode pembelajaran yang mendorong proses belajar yang lebih aktif, sehingga dapat mendorong aktivasi long term memory melalui pengenalan kasus yang realistik dan kontekstual sehingga dapat meningkatkan retensi kognitif peserta didik. ${ }^{2}$ Metode yang dapat dilakukan untuk meningkatkan kreativitas dan keaktifan mahasiswa, pendekatan student centered learning (SCL) yang berfokus kepada mahasiswa adalah metode PBL. ${ }^{3}$ Faktor yang mempengaruhi retensi kognitif, salah satunya adalah keterampilan metakognitif. Retensi dan keterampilan metakognitif dapat diterapkan pada berbagai macam strategi pembelajaran, salah satunya metode PBL. ${ }^{4}$ Menurut penelitian Adrian dalam teori Sausa mengindikasikan bahwa retensi akan bertahan $50 \%$ jika peserta didik belajar melalui diskusi, $75 \%$ melalui belajar sesama peserta didik, dan 90\% jika peserta didik mengaplikasikan pengetahuan yang dipelajari. ${ }^{5}$ Motivasi belajar peserta didik yang tinggi diawal pembelajaran mendapatkan hasil belajar yang maksimal dengan menggunakan model pembelajaran Blended Learning. ${ }^{6}$

Program studi Diploma IV Kebidanan Universitas Padjadjaran salah satu institusi pendidikan yang telah menggunakan metode $\mathrm{PBL}$, namun keterbatasan tenaga pendidik untuk melakukan Tri Dharma Perguruan tinggi diperlukan inovasi metode pembelajaran yang dapat mengatasi keterbatasan metode PBL. Metode ABLE-PBL merupakan metode pembelajaran PBL yang pelaksanaan identifikasi topik belajar pada pertemuan pertamanya dilakukan secara asynchronous-online, sedangkan tahap evaluasi belajar mandiri pada pertemuan kedua dilakukan secara tatap muka (offline). Aplikasi: http://husen. able-pbl.fk.unpad.ac.id. Peran tutor pada pertemuan pertama tutorial dengan metode ABLE-PBL digantikan oleh aplikasi ABLE-PBL (online).

Metode ABLE-PBL adalah salah satu inovasi pembelajaran yang dapat digunakan pada institusi pendidikan kebidanan yang memiliki keterbatasan jumlah tenaga pendidik namun tetap ingin mengoptimalkan proses pembelajaran dan menghasilkan kualitas lulusan yang kompeten sesuai dengan kebutuhan masyarakat.

\section{METODE}

Penelitian ini merupakan penelitian kuantitatif. Variabel dependent penelitian ini adalah asynchronous blended problem based learning, variabel independent adalah retensi kognitif dan motivasi.

Subjek penelitian ini adalah seluruh mahasiswa semester IV D4 Kebidanan Universitas Padjadjaran Jumlah sampel sebanyak 37 orang, yang memenuhi kriteria inklusi dan tidak memenuhi eksklusi. 
Desain penelitian ini adalah crossover (kontrol silang). Prosedur penelitian yaitu peneliti membagi sampel penelitian (mahasiswa) dalam dua kelompok, kelompok I (ABLE-PBL) dan kelompok II (PBL), kemudian kedua kelompok diberikan sub pokok bahasan (tutorial materi 1: kontrasepsi hormonal jangka pendek) yang sama namun menggunakan metode yang berbeda. Dua minggu berikutnya kedua kelompok diberikan sub pokok bahasan berikutnya (tutorial materi 2: kontrasepsi jangka panjang dan kontrasepsi mantap) namun metodenya ditukar, sehingga kelompok I menjadi kelompok kontrol (PBL) dan kelompok II menjadi kelompok intervensi (ABLE-PBL).

Retensi kognitif diukur pada kedua kelompok dengan kuesioner test kognitif, sebelum penelitian instrumen penelitian yaitu kuesioner test kognitif dan kuesioner motivasi telah dilakukan validitas dan reabilitas. Test kognitif dilakukan 3x yaitu posttest, retest 1 (2 minggu setelah posttest) dan retest 2 (4 minggu setelah posttest). Motivasi belajar diukur pada kedua kelompok dengan kuesioner motivasi (pre dan post). Pengujian statistik menggunakan mann-whitney test, wilcoxon test dan chi square test.

Penelitian ini telah mendapatkan persetujuan dari Komisi Etik Fakultas Kedokteran Universitas Padjadjaran nomor 103/UN6.KEP/EC/2018.

\section{HASIL DAN PEMBAHASAN}

Tidak ditemukan perbedaan skor retensi 1 dan retensi 2 antara kelompok intervensi (ABLE-PBL) dan kelompok kontrol (PBL), nilai $p>0,05$, seperti yang dapat dilihat pada Tabel 1. Materi 1: Kenaikan skor retensi 1-retensi 2 pada kelompok intervensi (ABLE-PBL) adalah 26,14\%, sedangkan pada kelompok Kontrol (PBL) kenaikan skor retensi 1-retensi 2 adalah 45,36\%. Materi 2: Kenaikan skor pada kelompok intervensi (ABLE-PBL) pada retensi 1 -retensi 2 adalah 4,38\%, sedangkan pada kelompok kontrol (PBL) kenaikan skor pada retest 1-retest 2 adalah 0,94\%. Perbedaan kenaikan pada kedua kelompok tidak menunjukkan hasil yang bermakna sehingga metode pembelajaran ABLEPBL maupun PBL dapat dikatakan sama.

Tabel 1. Perbedaan Skor Retensi Kognitif pada Kelompok ABLE PBL dan PBL

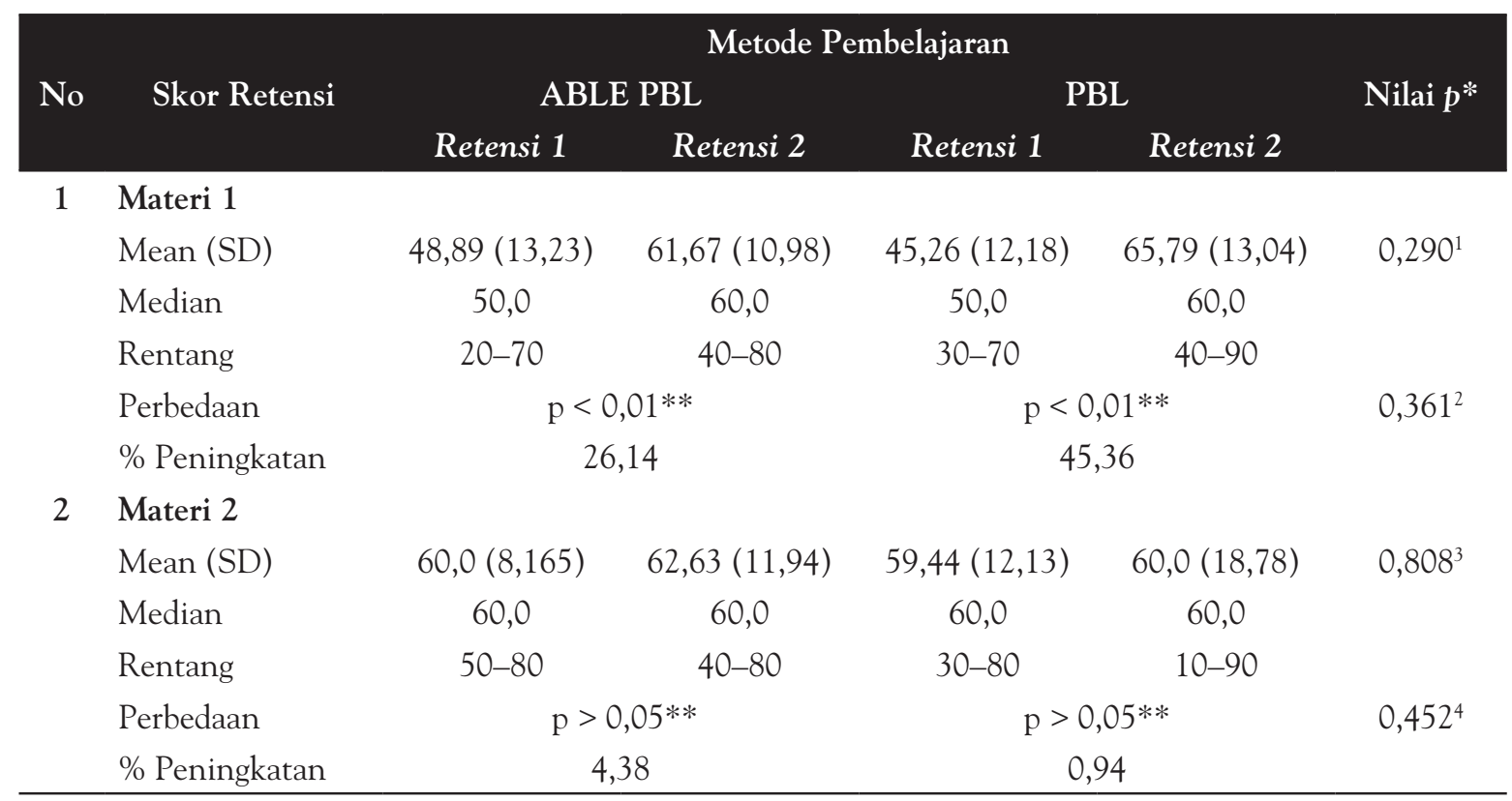

Keterangan: *Mann-Whitney **Wilcoxon

1. Nilai p untuk uji statistik perbedaan skor retensi 1 pada kedua kelompok pada materi 1

2. Nilai p untuk uji statistik perbedaan skor retensi 2 pada kedua kelompok pada materi 1

3. Nilai p untuk uji statistik perbedaan skor retensi 1 pada kedua kelompok pada materi 2

4. Nilai p untuk uji statistik perbedaan skor retensi 1 pada kedua kelompok pada materi 2 
Selain itu, tidak ditemukan pengaruh antara mahasiswa yang diberikan metode ABLE-PBL dan PBL pada retensi 1 dan retensi 2 dikedua materi, dengan nilai $\mathrm{p}>0,05$ seperti yang dapat dilihat pada Tabel 2.

Tabel 2. Pengaruh Metode ABLE-PBL dan PBL Terhadap Retensi Kognitif

\begin{tabular}{llccccc} 
& \multicolumn{5}{c}{ Metode Pembelajaran } \\
No & Kategori Retensi & \multicolumn{2}{c}{ ABLE PBL } & PBL & Nilai $\boldsymbol{p}^{*}$ \\
& & Retensi 1 & Retensi 2 & Retensi 1 & Retensi 2 & \\
\hline 1 & Materi 1 & & & & \\
& Sangat Baik & $5(27,8 \%)$ & $7(38,9 \%)$ & $6(31,6 \%)$ & $15(78,9 \%)$ & $0,986^{1}$ \\
Baik & $1(5,6 \%)$ & $7(38,9 \%)$ & $1(5,3 \%)$ & $3(15,8 \%)$ & \\
Cukup & $4(22,2 \%)$ & $3(16,7 \%)$ & $3(15,8 \%)$ & $0(0,0 \%)$ & $0,058^{2}$ \\
Kurang & $5(27,8 \%)$ & $1(5,6 \%)$ & $5(26,3 \%)$ & $1(5,3 \%)$ & \\
Sangat Kurang & $3(16,7 \%)$ & $0(0,0 \%)$ & $4(21,1 \%)$ & $0(0,0 \%)$ & \\
Materi 2 & & & & & \\
Sangat Baik & $16(84,2 \%)$ & $16(88,9 \%)$ & $17(89,5 \%)$ & $16(88,9 \%)$ & $0,315^{3}$ \\
Baik & $1(5,3 \%)$ & $2(11,1 \%)$ & $0(0,0 \%)$ & $1(5,6 \%)$ & \\
Cukup & $2(10,5 \%)$ & $0(0,0 \%)$ & $0(0,0 \%)$ & $0(0,0 \%)$ & $0,261^{4}$ \\
Kurang & $0(0,0 \%)$ & $0(0,0 \%)$ & $2(10,5 \%)$ & $0(0,0 \%)$ & \\
Sangat Kurang & $0(0,0 \%)$ & $0(0,0 \%)$ & $0(0,0 \%)$ & $1(5,6 \%)$ & \\
\hline
\end{tabular}

Keterangan : *Uji Chi Square

1. Pengaruh metode pembelajaran pada kedua kelompok terhadap retest 1 pada materi 1

2. Pengaruh metode pembelajaran pada kedua kelompok terhadap retest 2 pada materi 1

3. Pengaruh metode pembelajaran pada kedua kelompok terhadap retest 1 pada materi 2

4. Pengaruh metode pembelajaran pada kedua kelompok terhadap retest 2 pada materi 2

Tabel 3 di bawah ini menunjukan bahwa tidak metode ABLE-PBL dan PBL pada motivasi, dengan terdapat pengaruh antara mahasiswa yang diberikan nilai $\mathrm{p}>0,05$.

Tabel 3. Pengaruh Metode ABLE-PBL dan PBL Terhadap Motivasi Belajar

\begin{tabular}{|c|c|c|c|c|c|c|}
\hline \multirow{3}{*}{ No } & \multicolumn{6}{|c|}{ Metode Pembelajaran } \\
\hline & \multirow[t]{2}{*}{ Motivasi } & \multicolumn{2}{|c|}{ ABLE PBL } & \multicolumn{2}{|c|}{ PBL } & \multirow[t]{2}{*}{ Nilai $p^{*}$} \\
\hline & & Materi 1 & Materi 2 & Materi 1 & Materi 2 & \\
\hline \multirow[t]{3}{*}{1} & Pre & & & & & \\
\hline & Positif & 9 & 11 & 11 & 9 & $0,879^{1}$ \\
\hline & Negatif & 9 & 8 & 8 & 9 & \\
\hline \multirow[t]{3}{*}{2} & Post & & & & & \\
\hline & Positif & 11 & 8 & 8 & 11 & $0,408^{2}$ \\
\hline & Negatif & 7 & 11 & 11 & 7 & \\
\hline
\end{tabular}

Keterangan: *) Chi Square

1. Pengaruh metode pembelajaran pada kedua kelompok terhadap pretest motivasi

2. Pengaruh metode pembelajaran pada kedua kelompok terhadap posttest motivasi 
Hasil penelitian ini tidak bisa dibandingkan dengan penelitian lain karena sejauh ini belum terdapat penelitian yang membandingkan antara metode asynchronous blended problem based learning dengan metode problem based learning terhadap retensi kognitif. Namun demikian, tedapat penelitian-penelitian serupa lain yang sejalan dengan penelitian ini. Hasil penelitian ini sejalan dengan penelitian yang dilakukan De Jong $\mathrm{dkk}^{7}$ yang menyebutkan bahwa metode asynchronous online problem based learning memiliki hasil belajar yang sama dengan metode problem based learning. Akan tetapi, hasil penelitian ini berbeda dengan penelitian Hutasoit, ${ }^{8}$ yang menunjukan metode ABLE-PBL berpengaruh terhadap pengetahuan sebesar 8,838 kali dan aktivitas belajar sebesar 9,595 kali.

Faktor-faktor yang mempengaruhi keefektifan metode ABLE-PBL dan PBL diantaranya proses pembelajaran, pelatihan metode ABLE-PBL dan manual book, skenario kasus dan guide question, concept map, feedback, aplikasi ABLE-PBL, dan retest. Proses pembelajaran pada metode ABLE-PBL maupun metode PBL membentuk affective system (skenario kasus) dan working memory (diskusi, belajar mandiri dan feedback) serta membentuk proses berfikir metakognitif. Pelatihan metode ABLE-PBL telah diakukan kepada dosen mata kuliah dan mahasiswa sebagai subjek penelitian. Pelatihan pada mahasiswa dilaksanakan 2 hari dan setiap mahasiswa diberikan manual book ABLEPBL namun mahasiswa hanya mencoba latihan mengerjakan tutorial online satu kali. Pertemuan pertama online meeting terdapat guide question yang memudahkan peserta didik dalam menjawab pertanyaan kasus namun mahasiswa belum terbiasa dan tidak percaya diri dalam menjawab, salah satu faktornya karena mahasiswa terbiasa diarahkan oleh tutor pada saat tutorial. Kualitas skenario kasus berperan pada saat tutorial online dan tutorial offline. Pertemuan kedua (tutorial offline), para tutor berpendapat kualitas kasus sangat berperan saat diskusi kelompok pada kedua kelompok. Hal ini menjadi salah satu faktor tidak terdapat perbedaan antara kelompok ABLE-PBL dan PBL dalam peningkatan retensi kognitif mahasiswa.
Concept map. Proses pembelajaran pada kedua kelompok, ABLE-PBL maupun PBL mahasiswa diharuskan membuat concept map setelah tahap evaluasi belajar mandiri pada pertemuan kedua (offline). Membuat concept map dapat melatih meningkatkan retensi kognitif mahasiswa.

Kinerja tutor sebagai fasilitator dalam proses tutorial salah satunya memberikan feedback. Hasil penelitian menunjukan mahasiswa merasa senang apabila tutor dapat memberikan feedback. Hasil pengamatan data server semua tutor memberikan feedback pada semua mahasiswa yang mengisi secara online. Hal ini menjadi salah satu faktor tidak terdapat perbedaan antara kelompok ABLEPBL dan PBL dalam peningkatan retensi kognitif mahasiswa.

Aplikasi ABLE-PBL merupakan metode pembelajaran yang proses tutorialnya didesain seperti metode PBL, namun aplikasi ABLE-PBL ini memiliki keterbatasan dalam fitur hipotesis dan fitur feedback.

Retest cognitif sebanyak tiga kali, yaitu posttest, retest 1 dan retest 2 menjadi salah satu faktor yang mempengaruhi peningkatan retensi. Peneliti membuat tiga (3) tipe soal berbeda namun setiap soal mengukur capaian pembelajaran yang sama, yang bertujuan agar mahasiswa memahami materi bukan mengingat soal test.

Penelitian ini berbeda dengan penelitian De Jong $\mathrm{dkk},{ }^{7}$ metode asynchronous online problem based learning memiliki skor motivasi lebih tinggi dibandingkan dengan kelompok problem based learning. Menurut Keller, motivasi belajar dipengaruhi oleh empat komponen persepsi yaitu perhatian (attention), relevansi (relevannce), kepercayaan (confidence) dan kepuasaan (satisfaction). Setiap komponen memainkan peranan yang memotivasi peserta didik selama pembelajaran. ${ }^{9}$

Hasil penelitian juga menunjukan responden menyetujui metode ABLE-PBL merupakan metode inovasi untuk pembelajaran tutorial, mahasiswa menjadi lebih banyak diskusi dengan kelompok dan mencari informasi terkait kasus yang diberikan untuk pertemuan pertama (online) serta mengasah 
keterampilan mahasiswa dalam problem solving dan critical thinking (kelompok ABLE-PBL dan PBL), namun mahasiswa belum terbiasa mengerjakan tutorial online dan salah satu faktornya karena mahasiswa terbiasa diarahkan oleh tutor pada saat tutorial, sehingga salah satunya dapat mempengaruhi motivasi belajar.

\section{KESIMPULAN}

Metode asynchronous blended problem based learning dan metode problem based learning tidak memilki perbedaan dalam mempengaruhi retensi kognitif dan motivasi belajar mahasiswa.

\section{DAFTAR SINGKATAN}

ABLE-PBL: Asynchronous Blended Problem Based Learning

PBL : Problem Based Learning

SCL : : Student Centered Learning

\section{DAFTAR PUSTAKA}

1. World Health Organization. Global Strategy On Human Resources For Health : Workforce 2030. WHO. 2016.

2. Husen I. Teori bolu bantat. Bandung : Bitread Publishing. 2017.

3. Sianipar I, Hilmanto D, Siregar I. Hubungan kinerja tutor dan kualitas kasus skenario terhadap keefektifan kelompok pada metode belajar problem based learning. IJEMC. 2016; 3(2).

4. Nurisya K, Corebima A, Rohman F. Hubungan keterampilan metakognitif dengan retensi siswa pada pembelajaran biologi berbasis problem based learning (PBL) Di SMA Kota Malang. Seminar Nasional Pendidikan dan Saintek 2016 (ISSN: 2557-533X).

5. Adrian Y, Degeng IN, Utaya S. Pengaruh pembelajaran kooperatif terhadap retensi siswa sekolah dasar. Jurnal Pendidikan: Teori, Penelitian, dan Pengembangan. 2016;1(2):222-226.

6. Delialioglu D. Student engagement in blended learning environment with lecture-based and problem-based instructional approach. Educational Technology and Society. 2012;15(3): 310-22.

7. De Jong N, Verstegen DML, Tan FES. A comparison of classroom and online asynchronous problembased learning for students undertaking statistics training as part of a public health masters degree. Adv in Health Sci Educ. 2013;18:245-64.

8. Hutasoit D. Pengaruh asyncronous blended problem based learning terhadap tingkat pengetahuan dan aktivitas belajar mahasiswa diploma III kebidanan di STIKes Ahmad Yani. Universitas Padjadjaran. 2018.

9. Keller JM. Motivational design for learning and performance. Springer Science. 2010. 